\title{
VII. ON THE INFECTIVITY OF FLOORS GROSSLY CONTAMINATED WITH CULTURES OF B. PESTIS.
}

Yersin (1897) found in the earth of infected localities, both at the time of an epidemic and even after its disappearance, an organism which he described as exactly resembling the plague bacillus, but of less virulence. Yersin evidently believed this organism to be $B$. pestis and put forward the opinion that this microbe, which was capable of living in the soil, somehow, under favourable circumstances, infected rats and thus gave birth to epidemics. The identity of this organism with the $B$. pestis cannot be accepted without reserve, as at that time many of the cultural characteristics of $B$. pestis were not known, and as far as we can ascertain the point has not since been investigated.

That the infection of plague resides in the soil in some form, is a view which has been widely held. As a result of the evidence which was brought before it, the Indian Plague Commission (1901) concluded that the universal experience of plague in India proved that the principal source of infection is to be found in the houses, into which the infection of plague has been introduced, that, in short, plague is essentially a disease of locality. They point out, therefore, that it would be important to obtain information as to the presence or absence of the bacillus in houses suspected of being infective and as to whether it survives or multiplies as a saprophyte in these houses, special attention being paid to the floors. The report then goes on to record the fact that, in the very numerous series of examinations made in India, the plague bacillus has never been detected in the floors of infected houses by any trustworthy observer. As far as we know this bacteriological feat still remains unaccomplished. As regards the saprophytic existence in soil of the $B$. pestis, the following observations are to be noticed:-

Gladin (1898) found $B$. pestis to live three months in moist sterilised garden earth. Marsh (Indian Plague Commission, 1901), also working with sterilised materials, was able to isolate by culture this 
organism from moist sterilised garden earth 13 days after it had been contaminated, and from moist sterilised cow-dung for many months afterwards. These observations were confirmed by Rosenau (1901), who found that the plague bacillus lived for a long time in moist earth, but if the earth was allowed to dry and if the temperature was above $30^{\circ} \mathrm{C}$, it soon died out.

In the case of unsterilised earth most observers have failed to find the bacillus after a few days, but Gladin (1898) states that he recovered it after two months. Some experiments have recently been made by Captain Mackie, I.M.S., and Dr Winter in the Plague Research Laboratory, Bombay, with unsterilised earth from the floor of an ordinary native hut. To these experiments, which have not yet been published, we have the permission of Lt.-Col. Bannerman, I.M.S., Director of the Laboratory, to refer. Cow-dung earth from the floor of a native house was grossly contaminated with virulent cultures of $B$. pestis. For several days afterwards attempts were made by two different methods to recover the organism. The methods used were, (1) culture on plates made of Conradi-Drigalski medium; (2) inoculation into guinea-pigs, four animals being inoculated subcutaneously each day with an emulsion of a weighed quantity of the earth.

The following were the results obtained :-

(a) 24 hours after contamination: out of seven attempts the bacillus was recovered on every occasion by culture; the four animals all died of plague.

(b) 48 hours after contamination: on five occasions out of seven the organism was recovered by culture, while two out of the four animals died of plague.

(c) 72 hours after contamination: out of seven attempts the bacillus was recovered once, while three out of the four guinea-pigs died of plague.

(d) 96 hours after contamination: again only once, out of seven attempts, was the organism recovered by culture, while only one animal out of the four died of plague.

The experiments were continued for sixteen days, but on no further occasion was the plague bacillus isolated either by culture or by animal inoculation.

These observations, then, would go to show that the plague bacillus in the cow-dung floors of native houses does not only not multiply but 
soon dies out altogether; that, in short, it is incapable of leading a saprophytic existence in such a situation.

In our present observations we have confined our attention to the question of how long floors of two different types retain their infectivity after being grossly contaminated with virulent cultures of $B$. pestis. We have made no attempts to recover the organism by the method of culture, but have employed throughout the animal test.

\section{Nature of floors.}

In the native houses of Bombay, and, in fact, throughout India generally, there are two common types of floor to be met with, which, for the sake of brevity hereafter, we shall designate as Floor A and Floor B.

Floor $A$ consists of ordinary cow-dung plastered, when moist, on the top of earth which has been previously beaten down.

Floor B consists of what is known as "chunam." It is made of a mixture of sand and lime, put down moist and allowed to set.

In a small outhouse or go-down of the Laboratory, similar to many a house occupied by the natives of Bombay, two floors of the above description were prepared alongside one another. This go-down is a room of about $14 \times 7$ feet with a roof of ordinary country tiles. It has only two openings in the walls; one, small and high up, is loosely closed in with a board; the other, larger and opening down to the plinth, is fitted with an ordinary wooden door. Light is practically excluded and ventilation, as is usual in the poorer class of native house, is provided for only by the loosely fitting door and window and the country tiles of the roof. With these two floors three series of experiments were made. The average temperature was $80^{\circ} \mathrm{F}$., the maximum $86^{\circ} \mathrm{F}$., and the minimum $70^{\circ} \mathrm{F}$.

\section{SERIES I.}

In this series the floors were grossly contaminated with pure virulent broth cultures of $B$. pestis, which were the first subcultures from animals which bad died of acute plague. They were allowed to dry for 24 hours. Then each day for a period of five or six days scrapings were taken, emulsified in sterile broth and rubbed into a shaved and lightly scarified surface on the abdomen of a number of rats and 
guinea-pigs. Two experiments with each floor were made after this method.

\section{(a) Experiment I. Floor A.}

A patch of floor measuring about $2 \times 1 \frac{1}{2}$ feet was contaminated with 100 c.c. of a five-day-old broth culture of B. pestis. At the same time the culture was tested by inoculating a small portion by the cutaneous method into one guinea-pig and 10 rats. Of these animals, the guinea-pig and four rats died of typical plague, the former after ten days and the rats within six days. The floor was allowed to dry for 24 hours. Then, each day for four consecutive days, and again on the sixth and tenth days, scrapings were taken from the contaminated patch and emulsified with sterile broth. The emulsion was then rubbed into a shaved and scarified surface on the abdomen of ten rats and one guinea-pig. The result of this experiment is set forth in Table I, from which it is seen that one rat and the guinea-pig inoculated 24 hours after contamination, and again one rat and the guinea-pig inoculated 48 hours after contamination, died of plague. Further, it is seen that none of the animals, inoculated later than 48 hours after the floor was contaminated, contracted the disease. In this and all subsequent experiments, in the case of all animals which died, the diagnosis was verified by post-mortem examination and cultural tests. All animals which survived for 21 days were killed at the end of this time and if the post-mortem examination showed anything at all suspicious cultures were made. In all instances smears from the spleen were examined microscopically.

\section{Table I. Experiment I. Floor A.}

Contaminated on 30. xi. 05.

\begin{tabular}{|c|c|c|c|c|}
\hline \multirow[t]{2}{*}{$\begin{array}{c}\text { Date of } \\
\text { inoculation }\end{array}$} & \multicolumn{2}{|c|}{$\begin{array}{c}\text { Number of animals } \\
\text { inoculated }\end{array}$} & \multicolumn{2}{|c|}{$\begin{array}{l}\text { Number of animals } \\
\text { which died of } \\
\text { intercurrent disease }\end{array}$} \\
\hline & Rats & Guinea-pigs & Rats & Guinea-pigs \\
\hline 1. xii. 05 & 10 & 1 & 2 & 0 \\
\hline 2. xii. 05 & 10 & 1 & 0 & 0 \\
\hline 3. xii. 05 & 10 & 1 & 2 & 0 \\
\hline 4. xii. 05 & 10 & 1 & 2 & $\mathbf{0}$ \\
\hline 6. xii. 05 & 10 & 1 & $\mathbf{3}$ & 0 \\
\hline 10. xii. 05 & 10 & 1 & 1 & 0 \\
\hline
\end{tabular}

\begin{tabular}{cc}
$\begin{array}{c}\text { Number of animals } \\
\text { which developed } \\
\text { plague }\end{array}$ \\
\hline Rats & Guinea-pigs \\
1 & 1 \\
1 & 1 \\
0 & 0 \\
0 & 0 \\
0 & 0 \\
0 & 0
\end{tabular}

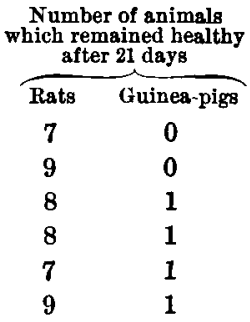




\section{(b) Experiment I. Floor B.}

The same culture as was employed in the experiment just described was used for this experiment, and the technique was exactly the same. It will be sufficient, therefore, to record the results in tabular form: from Table II it is seen that none of the animals, not even those inoculated 24 hours after the floor was contaminated, contracted plague.

\section{Table II. Experiment I. Floor B.}

Contaminated on 30. xi. 05.

\begin{tabular}{rcc}
$\begin{array}{c}\text { Date of } \\
\text { inoculation }\end{array}$ & $\begin{array}{c}\text { Number of animals } \\
\text { inoculated }\end{array}$ \\
\cline { 2 - 3 } 1. xii. 05 & 10 & $\begin{array}{c}\text { Guinea-pigs } \\
\text { Rats }\end{array}$ \\
2. xii. 05 & 10 & 1 \\
3. xii. 05 & 10 & 1 \\
4. xii. 05 & 10 & 1 \\
6. xii. 05 & 10 & 1 \\
10. xii. 05 & 10 & 1
\end{tabular}

$\begin{array}{cc}\begin{array}{c}\text { Number of animals } \\ \text { which died of } \\ \text { intercurrent disease }\end{array} \\ \begin{array}{cc}\text { Rats } \\ 2\end{array} & \begin{array}{c}\text { Guinea-pigs } \\ 1\end{array} \\ 1 & 0 \\ 3 & 0 \\ 0 & 0 \\ 1 & 0 \\ & 0\end{array}$

\begin{tabular}{cc}
$\begin{array}{c}\text { Number of animals } \\
\text { which developed } \\
\text { plague }\end{array}$ \\
\hline Rats & $\begin{array}{c}\text { Guinea-pigs } \\
0\end{array}$ \\
0 & 0 \\
0 & 0 \\
0 & 0 \\
0 & 0 \\
0 & 0
\end{tabular}

\begin{tabular}{cc}
$\begin{array}{c}\text { Number of animals } \\
\text { which remained healthy } \\
\text { after } 21 \text { days }\end{array}$ \\
\hline $\begin{array}{c}\text { Rats } \\
8\end{array}$ & $\begin{array}{c}\text { Guinea-pigs } \\
9\end{array}$ \\
9 & 1 \\
7 & 1 \\
10 & 1 \\
9 & 1 \\
\hline
\end{tabular}

\section{SERIES II.}

The experiments of this series were practically a repetition of those of Series I, the only modification being that, in order to imitate as far as possible the conditions pertaining in a native house, the floors were kept moist, water being daily sprinkled over the contaminated areas.

\section{(a) Experiment II. Floor A.}

The same area of floor as in the previous experiment was contaminated with about 50 c.c. of an eight day broth culture of $B$. pestis. This culture was the first remove from a white rat which had died of typical plague. At the same time as the floor was contaminated five rats and one guinea-pig were inoculated cutaneously with a few drops of the culture. Two of these rats and the guinea-pig died of typical plague; the former within five days and the latter after three days. The floor was allowed to dry for 24 hours. Then, each day for five consecutive days scrapings were taken from the contaminated area and emulsified in sterile broth. The emulsion was rubbed into a shaven 
and scarified surface on the abdomens of 10 rats and two guinea-pigs. The results are set forth in Table III, from which it is seen that only one guinea-pig, and that one inoculated 24 hours after the floor had been contaminated, died of plague. None of the animals inoculated later than 24 hours contracted the disease.

Table III. Experiment II. Floor A.

Contaminated on 27. xii. 05.

\begin{tabular}{ccc}
$\begin{array}{c}\text { Date of } \\
\text { inoculation }\end{array}$ & $\begin{array}{c}\text { Number of animals } \\
\text { inoculated }\end{array}$ \\
\cline { 2 - 3 } Rats & Guinea-pigs \\
29. xii. 05 & 10 & 2 \\
30. xii. 05 & 10 & 2 \\
31. xii. 05 & 10 & 2 \\
1. i. 06 & 10 & 2 \\
\end{tabular}

$\begin{array}{cc}\begin{array}{c}\text { Number of animals } \\ \text { which died of } \\ \text { intercurrent disease }\end{array} \\ \text { Rats } & \text { Guinea-pigs } \\ 3 & 0 \\ 2 & 1 \\ 0 & 0 \\ 0 & 0 \\ 2 & 0\end{array}$

\begin{tabular}{|c|c|}
\hline \multicolumn{2}{|c|}{$\begin{array}{c}\text { Number of animals } \\
\text { which developed } \\
\text { plague }\end{array}$} \\
\hline Rats & Guinea-pigs \\
\hline 0 & 1 \\
\hline 0 & 0 \\
\hline 0 & 0 \\
\hline 0 & 0 \\
\hline 0 & 0 \\
\hline
\end{tabular}

\begin{tabular}{|c|c|}
\hline \multicolumn{2}{|c|}{$\begin{array}{l}\text { Number of animals } \\
\text { which remsined healthy } \\
\text { after } 21 \text { days }\end{array}$} \\
\hline Rats & Guines-pigs \\
\hline 7 & 1 \\
\hline 8 & 1 \\
\hline 10 & 2 \\
\hline 10 & 2 \\
\hline 8 & 2 \\
\hline
\end{tabular}

(b) Experiment II. Floor B.

The same area of the floor as was used in Experiment $I$ with this floor was now contaminated with about 50 c.c. of an eight day broth culture of $B$. pestis. This culture was the first remove from a white rat which had died of acute plague. At the same time as the floor was contaminated five rats and one guinea-pig were inoculated cutaneously with a few drops of the culture. Of these animals, one rat and the guinea-pig died of typical plague, the rat after six days and the guinea-pig after eight days. The floor was allowed to dry for 24 hours and then tested as regards its infectivity in exactly the same manner as in the preceding experiment. The result is set forth in Table IV, from which it is seen that not a single animal contracted plague.

Table IV. Experiment II. Floor B.

Contaminated -on 27. xii. 05.

\begin{tabular}{lcc}
$\begin{array}{c}\text { Date of } \\
\text { inoculation }\end{array}$ & \multicolumn{1}{c}{$\begin{array}{c}\text { Number of animals } \\
\text { inoculated }\end{array}$} \\
\cline { 2 - 3 } 28. xii. 05 & 10 & 2 \\
29. xii. 05 & 10 & 2 \\
30. xii. 05 & 10 & 2 \\
31. xii. 05 & 10 & 2 \\
1. i. 06 & 10 & 2
\end{tabular}

$\begin{array}{cc}\begin{array}{c}\text { Number of animals } \\ \text { which died of } \\ \text { intercurrent disease }\end{array} \\ \overbrace{\text { Rats }}^{\text {Guinea-pigs }} \\ 2 & 0 \\ 3 & 0 \\ 2 & 0 \\ 1 & 0 \\ 1 & 0\end{array}$

\begin{tabular}{|c|c|}
\hline \multicolumn{2}{|c|}{$\begin{array}{l}\text { Number of animals } \\
\text { which developed } \\
\text { plague }\end{array}$} \\
\hline Rats & Guinea-pigs \\
\hline 0 & 0 \\
\hline 0 & 0 \\
\hline 0 & 0 \\
\hline 0 & 0 \\
\hline 0 & 0 \\
\hline
\end{tabular}

\begin{tabular}{cc}
$\begin{array}{c}\text { Number of animals } \\
\text { which remained healthy } \\
\text { after 21 days }\end{array}$ \\
\hline $\begin{array}{cc}\text { Rats } \\
8\end{array}$ & $\begin{array}{c}\text { Guinea-pigs } \\
7\end{array}$ \\
8 & 2 \\
9 & 2 \\
9 & 2 \\
\end{tabular}




\section{Summary.}

From these two series of experiments we can conclude that a cowdung floor, grossly contaminated with a virulent culture of B. pestis, can retain its infectivity for 48 hours but not longer, and that a chunam floor, treated in the same way, does not remain infective even for 24 hours.

\section{SERIES III.}

In this series of experiments a somewhat different technique was employed, the object being to ascertain how long a floor grossly contaminated remained infective for animals allowed to run free and to come in contact with it only in a natural manner. Over each floor, of the same materials as described above, but now enlarged to a size of $5 \times 4$ feet, a wire cage was placed. This cage, let into the ground on all sides, was without a bottom, an entrance being provided on the top. The floors were grossly contaminated with pure virulent cultures of $B$. pestis, a large amount, namely, between 350 and 600 c.c., being sprinkled over each area. The cultures were in all instances of full virulence, being only one remove from an animal which had died of acute plague.

A number of guinea-pigs were then placed in the cage and allowed to run free for several days. They were then taken out and segregated. In the several experiments of the series the interval between the contamination of the floors and the placing of the guinea-pigs in the cages was varied between one hour and 24 hours. Those animals which died were examined for post-mortem signs of plague; further, cultures were made, which cultures were tested by the methods we have already described.

Working in this way, we have made six experiments with each floor as follows :-

\section{(a) Experiment I. One hour's interval.}

In this experiment the floors were contaminated with 400 c.c. of broth cultures of $B$. pestis, the age of the cultures varying from three days to three weeks. One hour after this gross contamination twelve guinea-pigs were put into each cage and allowed to run about on the floors. At the time the guinea-pigs were put in it was noticed 
that both the floors were still very wet and especially that small pools of fluid still remained on floor B. The guinea-pigs were left in for 16 days, when the experiment was abandoned. By the 10th day, four animals, two from each floor, had died of typical plague. It is interesting to note that the primary buboes in these cases were in the following situations:-

Floor $\boldsymbol{A}$.

No. 1. Left inguinal region.

No. 2. Left axillary region.

Floor $B$.

No. 1. Right axillary region.

No. 2. Left axillary and deep cervical regions.

The other sixteen animals remained healthy.

\section{(b) Experiment II. Six hours' interval.}

In this experiment the floors were contaminated, each with 350 c.c. of broth cultures of $B$. pestis, varying in age from three to eight days. Six hours after this contamination, when the floors were still wet, especially Floor B, on which some small pools of fluid were lying, six guinea-pigs were put into each cage and allowed to run free. Four days afterwards these animals were removed and isolated singly. The six guinea-pigs which were on Floor A remained healthy, while of the six which came from Floor B four died of typical plague. The following are the situations of the buboes in these animals :-

No. 1. Right submaxillary and both cervical regions.

No. 2. Both submaxillary and left cervical regions.

No. 3. Right axillary and deep cervical regions.

No. 4. Left inguinal and left pelvic regions.

(c) Experiment III. Twelve hours' interval.

In this experiment the floors were contaminated, A with 600 c.c., B with 450 c.c., of broth cultures of $B$. pestis, varying in age from two to six days. The guinea-pigs, six into each cage, were put in twelve hours after this contamination. It was noted that the floors were still moist, but that no pools of culture fluid remained on Floor B. The animals were removed after four days and segregated singly. They all remained healthy. 


\section{(d) Experiment IV. Twelve hours' interval.}

This experiment was a repetition of No. 3. The cultures used varied in age from four to five days. It was again noticed that the floors were still moist, but that there were no pools on Floor B. The guinea-pigs were removed and segregated at the end of four days. It was then seen that the left hind leg of one of the animals from Floor A had been eaten away. This guinea-pig was the only one of the twelve which developed plague, buboes being present in both inguinal regions.

\section{(e) Experiment V. Twenty-four hours' interval.}

In this experiment Floor A was contaminated with 600 c.c., Floor B with 400 c.c., of broth cultures of B. pestis varying in age from six to twelve days. 24 hours after this contamination six guinea-pigs were placed in each cage. It was then noted that both floors were quite dry. The animals were removed after four days and isolated singly. All twelve remained healthy.

\section{$(f)$ Experiment VI. Twenty-four hours' interval.}

This experiment was a repetition of No. 5. The cultures used varied in age from three to eight days. At the time the guinea-pigs were put into the cages, the floors were quite dry. The animals were removed after four days and isolated. They all remained healthy.

\section{Table V. Series III.}
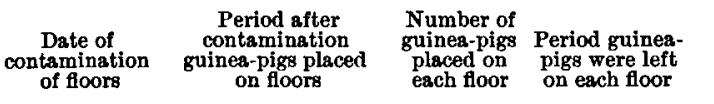

1. ii. 06

23. iii. 06

11. iii. 06

17. iii. 06

22. ii. 06

3. iii. 06
1 hour

\begin{abstract}
6 hours
12 hours

12 hours
\end{abstract}

12

\begin{abstract}
16 days
\end{abstract}
6

4 days

6

6

4 days

4 days

6

24 hours

24 hours

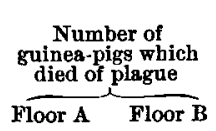

2

0

0

1

4 days $\quad 0$

4 days 0

\section{Remarks}

Floors quite wet; pools of fluid on $B$

Floors quite wet; pools of fluid on $B$

Floors moist, but no pools on $B$

Floor moist; no pools ; guinea-pig which died had its leg mutilated

Floor quite dry

Floor quite dry

The results of these six experiments of Series III can conveniently be thrown into tabular form (Table V). From this table it is seen that 
in the case of those guinea-pigs put on the floors one hour after contamination, two from each floor contracted the disease: that, if the floors were allowed to dry for six hours, none of the animals from the cow-dung floor, but four out of six from the chunam floor contracted plague; that, if the floors were allowed to dry still for twelve hours, only one animal from the cow-dung floor, which had been badly mutilated, died of plague; and finally, that if the animals were not put on until the floors were quite dry, namely, after twenty-four hours, none of them from either floor contracted the disease.

It would appear, therefore, that animals can walk about and sleep on floors, which have been grossly contaminated with virulent cultures of B. pestis, without contracting plague, if only an interval of about 24 hours is left between the contamination and the placing of the animals on the floors. This result is quite in harmony with the results of the go-down experiments already recorded, in which experiments guinea-pigs living on floors and eating food, both of which were contaminated with the urine and faeces of plague-infected animals, did not contract the disease as long as fleas were rigorously excluded.

\section{Summary of conclusions.}

(1) Floors of cow-dung grossly contaminated with $B$. pestis remain infective for 48 hours, the infectivity being tested by rubbing scrapings into susceptible animals.

(2) Floors of chunam grossly contaminated with $B$. pestis do not remain infective even for 24 hours, the infectivity being tested by rubbing scrapings into susceptible animals.

(3) Floors of cow-dung grossly contaminated with B. pestis remained infective for 12 hours but not for 24 hours to susceptible animals which were allowed to run about freely on them.

(4) Floors of chunam grossly contaminated with $B$. pestis remained infective for 6 but not for 12 hours, the infectivity being tested by allowing susceptible animals to run about freely on them.

\section{REFERENCES.}

Gladin, G. P. (1898), Die Lebensfähigkeit der Pestbacillen unter verschiedenen physikalischen Bedingungen. Centralblatt $f$. Bakteriol. xxIv. Part I. p. 588. Indian Plagde Commission (1901), vol. v. pp. 101, 102.

Rosenau, M. J. (1901), Bull. No. 4, Hyg. Lab., U.S. Public Health and Mar.-Hosp. Service.

Yersin (1897), Sur la peste bubonique. Annales Inst. Pasterer, vol. xI. p. 81. 